\title{
Modeling of Contact Angle versus pH and Derivation of Contact Angle versus Pressure in Deep Saline Aquifers under Geological Carbon Storage
}

\author{
Adango Miadonye ${ }^{1}$, Mumuni Amadu ${ }^{1}$ \\ ${ }^{1}$ School of Science \& Technology, Cape Breton University, Sydney, NS. Canada \\ Correspondence: Mumuni Amadu, School of Science \& Technology, Cape Breton University, Sydney, NS, Canada.
}

Received: Sep. 8, 2020 Accepted: Oct. 13, 2020 Online Published: Oct. 22, 2020

doi:10.5539/ijc.v12n2p19

URL: https://doi.org/10.5539/ijc.v12n2p19

\begin{abstract}
Geological storage of anthropogenic carbon dioxide is regarded as a technically and economically viable strategy for mitigating carbon dioxide induced climate warming.

Central to geological storage of anthropogenic carbon dioxide is the water rock interaction, which has a direct bearing on $\mathrm{pH}$ induced wettability evolution in saline aquifers. Consequently, understanding contact angle trend versus injected gas pressure is useful, considering its relationship to $\mathrm{pH}$ evolution in formation brine due to dissolved gas at prevailing temperatures and salinities. Several research works have published experimental data on contact angle versus pressure pertaining to geological conditions of anthropogenic carbon storage. In the present study, we have used thermodynamic theories relating to a surface charge model, contact angle and the classical Nernst equation to derive a logarithmic $\mathrm{pH}$ dependent contact angle equation. Considering the relationship between carbon dioxide solubility and pressure for a given temperature and salinity as well as the link between $\mathrm{pH}$ and the extent of solubility, we have plotted calculated contact angles versus corresponding pressures. Results of the plots obtained compare well with literature values. Therefore, given the lack of theoretical approach regarding contact angle versus pressure, our research work fills the knowledge gap considering the novelty in the derivation of the $\mathrm{pH}$ dependent contact angle equation.
\end{abstract}

Keywords: contact angle, surface charge; number density, ionization constant, interfacial tension, saline aquifer

\section{Introduction}

In recent times, researchers in the industry and academia have made concerted efforts to understand both the technical and geological aspects of carbon dioxide geological storage as well as its potential environmental impacts. In this regard, noteworthy data have been published on the effect of water rock interactions on contact angle/wettability, which affects the distribution of injected carbon dioxide and resident formation brine in the aquifer. (Jung \& Wan, 2012; Jung \& Wan, 2011, Kim et al., 2012). Much of contact angle data related to saline aquifer carbon storage have been obtained based on measurements on aquifer rock minerals under supercritical conditions that reflect deep saline aquifer geological conditions (Kim et al., 2012). The consensus of researchers so far regarding the water rock interaction and wettability evolution of saline aquifers under geological carbon storage is that aquifers will undergo dewetting (Saraji et al., 2013; Kim et al., 2012). Consequently, trends in contact angle versus pressure (Jung and Wan, 2011; Jung and Wan, 2013) which translates to $\mathrm{pH}$ decrease with pressure show increasing contact angle.

When carbon dioxide is injected into the formation above the threshold capillary pressure, a two-phase flow regime emerges where there is an interface between invaded gas and resident brine and an interface between resident brine and pore surface. Under this condition, it is possible to have a definite thickness of brine wetting film between the vapor phase and pore surface (Tokunaga, 2012) and an overlap of electric double layers and their repulsion. Following the dissolution of carbon dioxide and its subsequent hydration into carbonic acid and its dissociation, the adsorption of hydrogen ions on pore surface due to water rock interaction will reduce surface charge density, which will reduce double layer repulsion to destabilize the thin wetting film. These phenomena are what cause aquifer brine $\mathrm{pH}$ reduction and dewetting of aquifer rocks minerals by supercritical carbon dioxide (Saraji et al., 2013; Kim and Wan, 2012; Jung and Wan, 2011; Jung and Wan, 2012).

Thermodynamic theories on the effect of surface charge on wettability exist related to the low salinity water flooding (Yang et al., 2016; Mahani et al., 2017), silica model (Giovambattista et al., 2007) and in biotechnology (Eliaz, et al., 2009). Therefore, $\mathrm{pH}$ induced surface charge perturbation, which is the principal cause of disjoining pressure reduction by double layer repulsion reduction in saline aquifers under geological carbon storage is amenable to modeling from the 
theoretical point of view. We contend that $\mathrm{pH}$ induced surface charge regulation theories (Kosmulski, 2010)) can be exploited to embark on a theoretical understanding of dewetting trends versus pressure in saline aquifers under different conditions of geological carbon storage. Theoretically, for a saline aquifer under geological carbon storage, the solubility of carbon dioxide which is a precursor to carbonic acid formation and $\mathrm{pH}$ reduction in saline aquifers is controlled by salinity, pressure and temperature (Springer et al., 2012; Li et al., 2015. Therefore, brine pH will also depend on these physicochemical properties. Also, several experimental data on carbon dioxide-brine interfacial tension show that for a given temperature and salinity of aquifer, interfacial tension decreases with pressure and achieves a stable value at high pressures above the critical pressure (Chalbaud et al., 2010). The objective of this paper was to theoretically study dewetting trends (contact angle increase) versus pressure as revealed experimentally in the literature. Accordingly, we studied theoretically, $\mathrm{pH}$ induced dewetting of silica surface using our own derived equation and literature source data. We have shown a logarithmic relationship between $\mathrm{pH}$ and contact angle, which was vital for revealing observable contact angle versus pressure trend as found in the literature. For this reason, we chose silica as the predominant sandstone aquifer mineral for two reasons. First, sandstone formations are the most abundant with characteristic intergranular porosity (Ehrenberg \& Nadeau, 2005), which make them the best candidates for geological carbon storage. Second, several sequestration projects worldwide have sandstone formations as host geologic repositories (Labus et al., 2015; Liu et al., 2012; Zhou et al., 2010).

\section{Literature Review}

\subsection{Surface Charge Regulation Induced Wetting and Dewetting}

Surfaces may often be naturally charged, or electric fields may be employed to manipulate fluids, causing electric effects to be crucial components that influence wetting or dewetting phenomena. (Nita, et al., 2017). For instance, the behavior of polyelectrolyte adsorption on a substrate is dependent upon charge density, $\mathrm{pH}$, temperature, and ionic strength, which has been exploited to achieve desired wettability (Yoo et al., 1998). The mechanism of electrostatic induced wetting alteration is intimately linked to the isoelectric point (IEP-pzc) concept which is the electrokinetic equivalent of the point of zero charge $\mathrm{pH}$ (pzc) (Kosmulski, Isoelectric points and points of zero charge of metal (hydr)oxides: 50years after Parks' review, 2016). At the IEP, the particle surface is electrically neutral, and the magnitude of zeta potential is equal to zero (Moulin \& Roques, 2003). In light of the stabilization of the thin wetting film based on the classical theory of Derjaguin-Landau-Verwey-Overbeek (DLVO) (Hall et al., 1983); electrostatic repulsion stabilization of the film vanishes, leaving a predominant van der Waal contribution (Hano et al., 2012), which causes dewetting when adsorption of potential determining ions occur. Consequently, several reasons regarding wetting transition related to low salinity water flooding have been proposed, central to the entire subject of the double layer expansion by surface charge density increase which can be theoretically and quantitatively linked to disjoining pressure forces (Ding \& Rahman, 2017; (AlQuraishi \& AlHussinan, 2015; Mehana \& Fahes, 2018; Ashraf et al., 2010). In the context of dewetting of silica exposed to aqueous species of dissolved carbon dioxide (Kim et al., 2012; Jung and Wan, 2011; Jung and Wan, 2012), decrease in surface charge density due to adsorption of protons from dissolved and dissociated species of carbon dioxide will be responsible for decrease in double layer repulsion, which corresponds to decrease disjoining pressure forces and eminent dewetting. In light of $\mathrm{pH}$ dependence of solid-liquid interfacial (Amadu and Adango, 2019), adsorption of hydrogen ions on aquifer rocks following carbon dioxide injection will increase solid-liquid interfacial tension to a maximum (Parks, 1984) at the point of zero charge $\mathrm{pH}$, which in light of Young's phenomenological equation (Rusanov et al., 2004) corresponds to increase in contact angle.

\subsection{Vapor-Liquid Equilibrium Theory for Carbon Dioxide Solubility in Saline Aquifers}

When carbon dioxide is injected into the saline aquifer at a given temperature and salinity of formation brine, there will be solubility of brine in the vapor phase and solubility of vapor phase in brine phase such that phase mole fractions can be calculated as (Hassanzadeh et al., 2008):

$$
y_{\mathrm{H}_{2} \mathrm{O}}=\frac{K_{\mathrm{H}_{2} \mathrm{O}}^{o} a_{\mathrm{H}_{2} \mathrm{O}}}{\Phi_{\mathrm{H}_{2} \mathrm{O}} P_{t o t}} \exp \left(\frac{\left(P-P^{o}\right)^{-}}{R T}\right)
$$




$$
x_{\mathrm{CO}_{2}}=\frac{\Phi_{\mathrm{CO}_{2}}\left(1-y_{\mathrm{H}_{2} \mathrm{O}}\right) P_{t o t}}{55.508 \gamma_{x}^{\prime} K_{\mathrm{CO}_{2}(g)}^{0}} \exp \left(\frac{\left(P-P^{0}\right)-V_{\mathrm{CO}_{2}}^{-}}{R T}\right)
$$

In this equation, $\mathrm{K}_{\mathrm{CO}_{2}}^{o}$ is Henry's law constant for carbon dioxide solubility at reference pressure [bar mol ${ }^{-1} \mathrm{~kg} \mathrm{H}_{2} \mathrm{O}$ ] and $K_{\mathrm{H}_{2} \mathrm{O}}^{\mathrm{O}}$ is Henry's law constant for water at a reference pressure [bar mol $\left.{ }^{-1} \mathrm{~kg} \mathrm{H}_{2} \mathrm{O}\right], y_{\mathrm{H}_{2} \mathrm{O}}$ is the mole fraction of water in carbon dioxide phase [-], $x_{\mathrm{CO}_{2}}$ is the mole fraction of carbon dioxide in liquid phase [-], $T$ is absolute temperature $[\mathrm{K}], \mathrm{R}$ is universal gas constant $[\mathrm{J} / \mathrm{K}], \quad \bar{V}_{\mathrm{H}_{2} \mathrm{O}}$ is partial molar volume of water [cc/mol], partial molar volume of carbon dioxide [cc/mol], $\boldsymbol{P}_{t o t}$ is total pressure [bar], $P$ is pressure of interest [bar], $P^{o}$ is reference pressure, $\Phi$ phase fugacity, $\gamma_{x}^{\prime}$ is an activity coefficient for carbon dioxide.

Based on the mole fractions, the solubility of carbon dioxide in brine is calculated using the following equation (Portier and Rochelle, 2005

$$
m_{\mathrm{CO}_{2}}=K^{o}\left(T, P_{r e f}\right) \frac{\varphi_{\mathrm{CO}_{2}} x_{\mathrm{co}_{2}}}{\gamma^{\prime} K_{\mathrm{CO}_{2}}^{\mathrm{H}}\left(T, P_{\mathrm{H}_{2} \mathrm{O}}^{\mathrm{sat}}\right)} \exp \left[\left(\frac{-}{V_{\mathrm{CO}_{2}}^{\infty}}\right)\left(P-P_{\mathrm{H}_{2} \mathrm{O}}^{\mathrm{sat}}\right)\right]
$$

In which $\gamma^{\prime}$ is the salting out effect of carbon dioxide in sodium chloride solution, $m_{\mathrm{CO}_{2}}$ is the solubility of carbon dioxide in brine $\left[\mathrm{mol} / \mathrm{dm}^{3}\right]$ and $\vec{V}_{\mathrm{CO}_{2}}^{-\infty}$ is the partial molar volume of carbon dioxide at infinite dilution $\left[\mathrm{mol} / \mathrm{dm}^{3}\right]$.

\subsection{Theoretical Development}

\subsubsection{Linking $\mathrm{pH}$ to Formation Brine Salinity and Temperature and Pressure}

The carbon dioxide system in brine is characterized by four measurable parameters, namely the total alkalinity, the total inorganic carbon consisting of the sum of dissolved carbon dioxide (carbonate, and the bicarbonate), the $\mathrm{pH}$ and either the fugacity of carbon dioxide or its partial in the vapor phase (ref). At a given temperature and salinity of formation brine, carbon dioxide dissolves and hydrate to form carbonic acid in accordance with the following equation (Frank, et al., 2002):

$$
\mathrm{CO}_{2}+\mathrm{H}_{2} \mathrm{O} \leftrightarrow \mathrm{H}_{2} \mathrm{CO}_{3} \leftrightarrow \mathrm{H}^{+}+\mathrm{HCO}_{3}^{-}
$$

The first dissociation constant of constant of carbonic acid from Eq. (11) is given as (ref).

$$
K_{\mathrm{CO}_{2}}^{1}=\frac{\left\lfloor\mathrm{H}^{+}\left\lfloor\mathrm{HCO}_{3}^{-}\right\rfloor\right.}{\left[\mathrm{H}_{2} \mathrm{CO}_{3}\right]}
$$


In this equation, $\mathrm{K}_{\mathrm{CO}_{2}}^{1}$ is the first dissociation constant of carbonic acid and square bracket denotes the activity of species, which is the product of species activity coefficient and molar concentration.

In Eq. (5), the extent of dissociation of the mixture $\mathrm{CO}_{2}+\mathrm{H}_{2} \mathrm{O}$ into $\mathrm{H}^{+}+\mathrm{HCO}_{3}^{-}$ions is related to the ratio of the sum of the molar conductance of the mixture and the sum of the molar conductance of the ions. Assuming $\alpha$ moles per liter is the amount of dissolved and hydrated carbon dioxide of carbonic acid that dissociates to establish the equilibrium expressed by Eq. (5) can be written based on stoichiometry as:

$$
K_{\mathrm{CO}_{2}}^{1}=\frac{[\alpha \rrbracket \alpha]}{\left.\operatorname{con}_{\mathrm{H}_{2} \mathrm{CO} 3}-\alpha\right]}
$$

Where $\mathrm{CON}_{\mathrm{H}_{2} \mathrm{CO} 3}$ is the activity of carbonic acid initially present.

Assuming $\mathrm{COn}_{\mathrm{H}_{2} \mathrm{CO} 3}$ is equal to the solubility of carbon dioxide at prevailing pressure temperature and pressure, Eq. (6) can be written based on the solubility as:

$$
K_{\mathrm{CO}_{2}}^{1}=\frac{[\alpha \rrbracket[\alpha]}{\left[m_{\mathrm{CO} 2}-\alpha\right]}
$$

Equation. (7) is a quadratic equation in alfa and the solution using the quadratic theory gives $\alpha$ as:

$$
\alpha=\frac{K_{\mathrm{CO}_{2}}^{1} \pm \sqrt{\left(\left(\mathrm{K}_{\mathrm{CO}_{2}}^{1}\right)^{2}+4 K_{\mathrm{CO}_{2}}^{1} m_{\mathrm{CO}_{2}}\right)}}{-2}
$$

In line with the carbon dioxide dissociation constant being temperature and salinity dependent (Aissa et al., 2015) its value will reflect these physicochemical properties.

Using the chemical definition of $\mathrm{pH}$, the $\mathrm{pH}$ of water with a given salinity, temperature and pressure in a saline aquifer under geological carbon storage will be given from Eq. (8) as:

$$
p H=\log \left(\gamma \frac{K_{\mathrm{CO}_{2}}^{1} \pm \sqrt{\left(\left(K_{\mathrm{CO}_{2}}^{1}\right)^{2}+4 K_{\mathrm{CO}_{2}}^{1} m_{\mathrm{CO}_{2}}\right)}}{-2}\right)^{-1}
$$

In which $\gamma$ is the activity coefficient of hydrogen ion in solution.

Activity coefficient is related to ionic strength as (Schneider et al., 2004):

$$
\log \gamma=\frac{A z_{i}^{2} \sqrt{I}}{1+B a_{o} \sqrt{I}}
$$

$A$ is a constant relating to the solvent $z_{i}$ is the charge of the ion $B$ is a constant relating to the solvent, $a_{o}$ is a constant relating to the effective diameter of the ion in solution $I$ is the ionic strength of the solution

In this Eq. (8), $\mathrm{pH}$ will be calculated using the positive solution.

Henceforth Eq. (9) will be written to reflect salinity, temperature and pressure dependence of $\mathrm{pH}$ as: 


$$
p H(P, T, S)=\xi(P, T, S)=\log \left(\gamma \frac{K_{\mathrm{CO}_{2}}^{1} \pm \sqrt{\left(\left(K_{\mathrm{CO}_{2}}^{1}\right)^{2}+4 K_{\mathrm{CO}_{2}}^{1} m_{\mathrm{CO}_{2}}\right)}}{-2}\right)^{-1}
$$

The temperature and salinity dependence of the first ionization constant of carbonic acid will be invoked. This is given in the literature as (Aissa et al., 2015):

$$
\begin{aligned}
& \ln K_{\mathrm{CO}_{2}}^{1}(T, S)=\frac{-2936978}{T^{2}}+\frac{17883}{T}-41.4589+ \\
& \left(\frac{1141179}{T^{2}}-\frac{7220.094}{T}+13.40776\right) \sqrt{I}-1.414245 I+0.2677258 I^{3 / 2}
\end{aligned}
$$

In this equation, $\mathrm{T}$ is the absolute temperature $[\mathrm{K}]$ and $\mathrm{I}$ is the ionic strength $\left[\mathrm{moll}^{-1}\right]$ which corresponds to salinity $\mathrm{S}$

\subsubsection{Derivation of pH Dependent Contact Angle Equation}

In line with the effect of surface charge on the stability of the thin wetting film (Ciunel et al., 2005) and the theoretical aspect of surface charge density effect on contact angle (Puah et al., 2010), which has a direct bearing on wettability, the derivation of a $\mathrm{pH}$ dependent contact angle equation is necessary to achieve our principal objective. In this regard, we will assume a clean silica surface where the surface is characterized by a definite number density of surface hydroxyl functional groups or silanol (Zhuravlev \& Potapov, 2006 ). We will further assume that the surface of the silica is in contact with a predominantly sodium chloride brine (Hanor, 1994). Given that the $\mathrm{pH}$ of saline aquifers under normal conditions of geological storage is near neutral (Cooke et al., 2000) and the point of zero charge $\mathrm{pH}$ of silica is on the average 3 (Amadu \& Miadonye, 2017), the initial pH in the captive bubble method used by Farokhpoo et al., (2013) (see Figure 1), would be above the point of zero charge $\mathrm{pH}$. The surface of silica typically exhibits amphoteric behavior and becomes charged from protonation/ deprotonation reactions (Illés \& Tombácz, 2006): The following equilibrium reactions will describe the ionization of surface hydroxyl groups above the point of zero charge pH (Revil, 1998; Azam et al. 2013):

$$
\equiv \mathrm{SiOH} \rightarrow \equiv \mathrm{SiO}^{-}+\mathrm{H}^{+}
$$

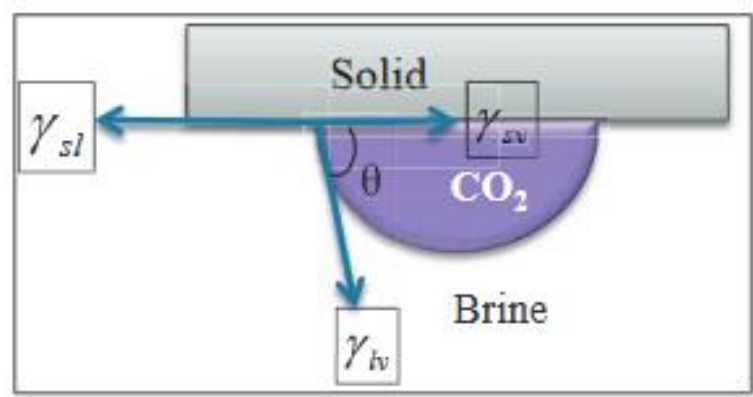

Figure 1. Schematic view of a sessile-drop contact angle system Farokhpoor et al., 2013)

The intrinsic ionization constants for Eq. (13) is $K_{a}$.

The derivation of the surface charge density assumes formation brine in contact with pore surface consisting predominantly of a one-meter square of surface ionizeable groups (silanol).

At a given temperature and salinity, dissolution of carbon dioxide will provide hydrogen ions in solution. Above the point of zero charge $\mathrm{pH}$ of silica, ionizable surface groups will produce negatively charged sites which will favor hydrogen ion adsorption. Based on the Gibbs excess equation (Chattorage, 2001) the following can be written to link change in solid-liquid interfacial tension to hydrogen ion adsorption:

$$
d \gamma_{S L}=-\Gamma R T d \ln \left(H^{+}\right)=-R T \Gamma 2.303 d \log \left(H^{+}\right)=R T \Gamma 2.303 d p H
$$

In this equation, $\Gamma$ is surface coverage $\left[\mathrm{molm}^{2}\right], R$ is the universal gas constant $\left[\mathrm{Jmol}^{-1} \mathrm{~K}^{-1}\right]$ and $H^{+}$is hydrogen ion concentration. 
Multiplying the top and bottom of the righthand side by Faraday's constant gives:

$$
d \gamma_{S L}=-\Gamma R T d \ln \left(H^{+}\right)=-R T \Gamma 2.303 d \log \left(H^{+}\right)=\frac{2.303 R T F d p H}{F}=\frac{2.303 R T \sigma}{F} d p H
$$

In this equation, $\sigma$ is the surface charge density.

From Young's equation (Makkonen, 2016) the following can be written:

$$
\gamma_{L V} d \cos \theta=-d \gamma_{S L}
$$

Substituting for change in solid-liquid interfacial tension from Eq. (16) into Eq. (15) and solving for pH derivative of the cosine of contract angle gives:

$$
\frac{d \cos \theta}{d p H}=-\frac{2.303 R T \sigma}{F \gamma_{L V}}
$$

In this equation, $\theta$ is contact angle-degrees, $p H$ is the negative logarithm to base 10 of the hydrogen ion activity of aqueous solution in contact with solid surface, $F=$ Faradays constant $\left[\mathrm{Cmol}^{-1}\right], \sigma$ is surface charge density-[ $\left.\mathrm{Cm}^{-2}\right], R$ is universal gas constant $\left[\mathrm{Jmol}^{-1} \mathrm{~K}^{-1}\right], T$ is absolute temperature, $\gamma$ is interfacial tension between fluid phases $\left[\mathrm{Nm}^{-1}\right]$.

If the charge density is predominantly due to a single class of dissociable functional group with a distinct ionization constant the at any $\mathrm{pH}$ of the aqueous solution the surface charge density relationship to bulk solution $\mathrm{pH}$ is given as (Godt, 1981)

$$
\begin{gathered}
\sigma=-\frac{\sigma_{T} K_{a}}{K_{a}+\left[H^{+}\right]_{o}} \\
{\left[H^{+}\right]_{o}=\left[H^{+}\right]_{B} e^{\left(\frac{-e \psi_{o}}{k_{B} T}\right)}}
\end{gathered}
$$

In which $\left\lfloor H^{+}\right\rfloor$is the hydrogen ion activity at the surface of the solid in contact with an electrolyte []$,\left\lfloor H^{+}\right\rfloor_{B}$ is the hydrogen ion activity of bulk aqueous solution $\left[\right.$ moll- $\left.^{-1}\right], \psi_{o}$ is the surface potential of solid surface in contact with an electrolyte solution [V ], $k_{B}$ is Boltzmann's constant [ ], $T$ is absolute temperature [K] and $\sigma_{T}$ is the maximum surface charge density.

Using the theoretical definition of $\mathrm{pH}$, the following can be written (Behrens \& Grier, 2001)

$$
\left\lfloor H^{+}\right\rfloor_{B}=10^{-p H}
$$

Substitution of Eq. (19) and Eq. (20) into Eq. (18) gives surface charge density as:

$$
\sigma=-\frac{\sigma_{T} K_{a}}{K_{a}+10^{-p H} e^{\left(\frac{e \psi_{o}}{k_{B} T}\right)}}
$$

The maximum surface charge density for a given dissociable site concentration is given as 


$$
\sigma_{T}=e N_{s}
$$

In which $e$ is the electronic charge [C] and $N_{s}$ is the number density of surface ionizable group $\left[\mathrm{m}^{-2}\right]$

The relationship between surface potential, $\mathrm{pH}$ of bulk aqueous solution and the point of zero charge $\mathrm{pH}$ is given by the Nernst equation as (Fairbank et al., 1997):

$$
\psi_{o}=-2.303 \frac{k_{B} T}{e} \Delta p H=2.303 \frac{k_{B} T}{e}\left(p H-p H_{P Z C}\right) \quad \text { In which } p H_{p z c} \text { is the }
$$

point of zero charge $\mathrm{pH}$ of solid surface and $\mathrm{pH}$ is negative logarithm to base 10 of the hydrogen ion activity of aqueous solution in contact with the solid surface and $k_{B}$ is Boltzmann's constant.

Substitution into Eq. (23) into Eq. (17) and separation of variables gives:

$$
d \cos \theta=-\frac{2.303 R T N_{s} K_{a} e}{F \gamma_{L V}}\left[\frac{10^{(p H)}}{K_{a} 10^{p H}+e^{2.303\left(p H_{P Z C}-p H\right)}}\right] d p H
$$

Theoretically, Eq. (24) gives the contact angle change on silica/pore surface due to $\mathrm{pH}$ changes following acidification of brine by carbon dioxide injection.

Integration gives:

$$
\cos \theta=\frac{a\left(\ln \left(\frac{e^{-c p H-\ln 2 p H}\left(b e^{c p H+\ln 5 p H+\ln 2 p H+e^{c d}}\right)}{b}\right)+c p H+\ln 2 p H\right)}{b(c+\ln 5+\ln 2)}
$$

Where:

$$
a=\frac{2.303 R T N_{s} e}{F \gamma_{L V}}
$$

$b=K_{a}$

$c=2.303$

$d=p H_{p z c}$

\subsection{Prediction of Contact Angle Trend under Geological Carbon Storage}

\subsubsection{Carbon Dioxide Solubility Data}

Based on the thermodynamic concepts of vapor liquid equilibrium presented in Section 2.2 of the present study, Duan and Sun, (2003) (Duan \& Sun, 2003) have measured excellent data on carbon dioxide solubility in brine versus pressure and temperature under varying degrees of salinity encountered under geological carbon storage, covering different temperatures and pressures that reflect anticipated supercritical conditions of geological storage (Dávila et al., 2016). Solubility data have also been published (Spycher at al.,2005).

Based on Hanor's (Hanor, 1994) classification of sedimentary basin brine, we assumed a sodium chloride dominated saline aquifer brine. Therefore, we extracted solubility data from Duan and Sun (2003) and Spycher et al., (2005) covering anticipated salinities, temperature and pressure for geological storage. We used solubility data at $333.15 \mathrm{~K}$ from both references.

We also assume the predominant surface ionizable groups on the surface of sandstone are silanols.

We chose 3 different concentrations of aqueous sodium chloride solution. They are $1 \mathrm{M}, 0 \mathrm{M}, 2 \mathrm{M}$ and $4 \mathrm{M}$. Concentrations of 1 to $4 \mathrm{M}$ can be found in formation brines (Jafari \& Jung, 2020). 
To use Eq. (25) for $\mathrm{pH}$ calculation, the temperature and salinity dependent first ionization constant was calculated using Eq. (12) with the help of Excel. Corresponding salinities and temperature (333.15 K) found in the cited references were this purpose. That means values of ionization constants were calculated for all salinities employed in the cited literature. To calculate $\mathrm{pH}$ versus pressure for a set of salinities and temperatures corresponding to the cited literature, values of calculated ionization constants were substituted into Eq. (11).

To calculate contact angle versus $\mathrm{pH}$, Eq. (25) was used with all the required physical constants. Excel was used for the calculation, whereby the $\mathrm{pH}$ calculated versus pressure using Eq. (25) and the solubility versus pressure for a set of salinities and temperatures extracted from the cited literature were used as variables.

To calculate $\mathrm{pH}$ using Eq (11), the activity coefficient of hydrogen ion at every pressure at a given temperature and salinity was calculated using Eq (10), which was then multiplied by the corresponding hydrogen ion concentration. Calculated $\mathrm{pH}$ values were then substituted into Eq. (25) with corresponding calculated parameters.

Experimental works so far indicate that the interfacial tension between carbon dioxide and brine decreases with pressure for a give temperature and attains a stable value at high pressures above 10 to $15 \mathrm{MPa}$ (Chalbaud et al., 2010), while increasing with salinity at a given temperature carbon dioxide-brine interfacial tension was determined as a function of temperature and salinity Using Appendix A: Interfacial tensions for $0, \mathrm{M}, 1 \mathrm{M}, 2 \mathrm{M}$ and $4 \mathrm{M}$ were $0.025 \mathrm{Nm}^{-1}, 0.029$ $\mathrm{Nm}^{-1}, 0.032 \mathrm{Nm}^{-1}$ and $0.036 \mathrm{Nm}^{-1}$ respectively. Appendix A was used for deducing interfacial tension values.

Substitution of deduced carbon dioxide-brine interfacial tension at a corresponding temperature and salinity into Eq containing corresponding calculated parameters facilitated calculation of contact angle versus $\mathrm{pH}$ for different salinities of brine. Since $\mathrm{pH}$ is calculated as a function of carbon dioxide pressure for different salinities at a given temperature, calculated contact angles can be plotted against pressure for a given temperature and salinity.

The value of dissociation constant Ka used in this study is 5.7 molar (Dove \& Craven, 2005). The value of the universal gas constant used is $3.8 \mathrm{Jmol}^{-1} \mathrm{~K}^{-1}$ ( (Katmar-Software, 2020). The activity coefficient of hydrogen ion was calculated using We used an effective hydration radius of $0.03 \mathrm{~nm}$ for hydrogen ion (Lee, 2020). The number density of surface silanols is $4.5 \mathrm{~m}^{-2}$ (Zhuravlev \& Potapov, 2006). The value for the point of zero charge $\mathrm{pH}\left(\mathrm{pH}_{p z c}\right)$ of silica surface used in this study is 3 (Amadu and Adango, 2017).

\section{Results and Discussion}

Generally, the temperature of carbon dioxide in deep saline aquifers will be equal to or above critical pressure. At such depths, the pressure of carbon dioxide due partly to pore pressure and partly to overburden pressure will be far above critical. Consequently, the interfacial tension is likely to achieve a stable value in accordance with observed trends from experimental data (Chalbaud et al., 2010). Therefore, integration of the theoretical model ((Eq.24)), assuming constant values of interfacial tension at given salinity and temperature is justifiable. Solubility data provided by Dun and Sun and Spycher et al (2005) reflect temperature, pressure and salinity conditions of geological carbon storage. Reaction of supercritical $\mathrm{CO}_{2}$ with brine causes a significant $\mathrm{pH}$ drop to 3 units in the saline pore fluid (Qafoku et al., 2015), due to carbonic acid (as dissolved CO2) in the brine (Rathnaweera et al., 2016), which is confirmed by Table 1

Table 1. Calculated contact angle versus pressure for Duan and Sun (2003) solubility data

\begin{tabular}{c|c|c|c|c|c}
\hline \multicolumn{2}{l}{} & \multicolumn{3}{l}{ Results for 4 molar solution } \\
\multicolumn{2}{l}{ Results for 0 molar solution } & Contact Angle- & Pressure-MPa & $\mathrm{pH}$ & Contact Angle- $^{\mathrm{o}}$ \\
\hline Pressure-MPa & $\mathrm{pH}$ & 57.32 & 0.1 & 3.10 & 70.41 \\
\hline 0.1 & 4.53 & 71.46 & 1 & 2.47 & 71.46 \\
\hline 1 & 4.11 & 59.03 & 10 & 1.97 & 72.17 \\
\hline 10 & 3.84 & 59.12 & 30 & 1.87 & 72.23 \\
\hline 30 & 3.81 & 59.19 & 40 & 1.86 & 72.24 \\
\hline 40 & 3.78 & 59.26 & 60 & 1.82 & 72.25 \\
\hline 60 & 3.75 & 59.30 & 70 & 1.80 & 72.25 \\
\hline 70 & 3.74 & 59.33 & 80 & 1.78 & 72.25 \\
\hline 80 & 3.72 & 59.36 & 90 & 1.75 & $7 \ldots$ \\
\hline 10 & 3.71 & 59.39 & 100 & 1.73 & 72.24 \\
\hline 110 & 3.70 & 59.42 & 110 & 1.71 & 72.23 \\
\hline 120 & 3.69 & 59.42 & 120 & 1.69 & 72.22 \\
\hline 130 & 3.68 & 59.48 & 130 & 1.68 & 72.21 \\
\hline 140 & 3.67 & 59.50 & 140 & 1.67 & 72.18 \\
\hline
\end{tabular}

and Table 2, showing $\mathrm{pH}$, pressure and contact angles for different salinities at 333.15. Kharaka et al., 2006 have also reported $\mathrm{pH}$ drop of formation brine from 7 to $2 \mathrm{pH}$ units. (Kharaka, et al., 2006) 
In all tables, calculated values of $\mathrm{pH}$ and contact angle are reported to 2 decimal places. In Table 1 , while results for 0 molar solution show consistent increase in contact angle with $\mathrm{pH}$ decrease, there is a slight deviation for 4 molar solution at pressures above $100 \mathrm{MPa}$ and this is probably due to the rounding off to 2 decimal places.

Table 2. Calculated contact angle versus pressure for Duan and Sun (2003) solubility data for 2 molar solution

Results for 2 molar solution

\begin{tabular}{c|c|c}
\hline Pressure-MPa & $\mathrm{pH}$ & Contact Angle- $^{0}$ \\
\hline 0.1 & 4.16 & 60.79 \\
\hline 1 & 3.71 & 61.82 \\
\hline 5 & 3.49 & 62.36 \\
\hline 20 & 3.4 & 62.59 \\
\hline 30 & 3.38 & 62.63 \\
\hline 40 & 3.37 & 62.66 \\
\hline 50 & 3.36 & 62.68 \\
\hline 60 & 3.35 & 62.70 \\
\hline 70 & 3.34 & 62.73 \\
\hline 90 & 3.33 & 62.76 \\
\hline 110 & 3.32 & 62.79 \\
\hline 120 & 3.31 & 62.81 \\
\hline 140 & 3.30 & 62.84 \\
\hline 150 & 3.29 & 62.85 \\
\hline 170 & 3.28 & 62.87 \\
\hline 200 & 3.27 & 62.90 \\
\hline
\end{tabular}

Table 3. Calculated contact angle versus pressure for Spycher et al., (2005) solubility data

\begin{tabular}{c|c|c|c|c|c}
\hline \multicolumn{2}{l}{} & \multicolumn{3}{l}{ Results for 2 molar solution } \\
\hline Results for 1 molar solution & Contact Angle- ${ }^{0}$ & Pressure-MPa & $\mathrm{pH}$ & Contact Angle- $^{-}$ \\
\hline Pressure-MPa & $\mathrm{pH}$ & 68.67 & 4 & 2.86 & 71.72 \\
\hline 4 & 3.14 & 68.89 & 6 & 2.78 & 71.91 \\
\hline 6 & 3.06 & 69.06 & 8 & 2.71 & 72.05 \\
\hline 8 & 3.0 & 69.13 & 10 & 2.69 & 72.11 \\
\hline 10 & 2.98 & 69.15 & 12 & 2.68 & 72.13 \\
\hline 12 & 2.97 & 69.18 & 14 & 2.67 & 72.16 \\
\hline 14 & 2.96 & 69.29 & 28 & 2.66 & 72.24 \\
\hline 18 & 2.93 & 69.29 & 20 & 2.64 & 72.25 \\
\hline 20 & 2.93 & & & &
\end{tabular}


Table 4. Calculated contact angle versus pressure for Spycher et al., (2005) for 4 molar solubility data

Results for 4 molar solution

\begin{tabular}{c|c|c}
\hline Pressure-MPa & $\mathrm{pH}$ & Contact Angle- $^{\circ}$ \\
\hline 4 & 2.36 & 75.59 \\
\hline 6 & 2.31 & 75.69 \\
\hline 8 & 2.25 & 75.82 \\
\hline 10 & 2.20 & 75.91 \\
\hline 12 & 2.18 & 75.95 \\
\hline 14 & 2.17 & 75.96 \\
\hline 18 & 2.16 & 75.98 \\
\hline 20 & 2.16 & 75.99 \\
\hline
\end{tabular}

Figure 2 shows plots of contact angle versus pressure of salinity deduced from the present study based on contact angle versus pH model (Eq. (25)), using Spycher et al (2005) solubility data at 333.15 K. The figure shows that above $7 \mathrm{MPa}$, contact angle appears to have a stable value with pressure, consistent with the similar plots (Jung \& Wan, 2012) (See Appendix B). Figure 3 also shows a similar plot based on Dun and Sun solubility data. The figure shows that below the critical pressure of carbon dioxide, the pressure gradient of contact angle is steep for all plots at a given temperature.

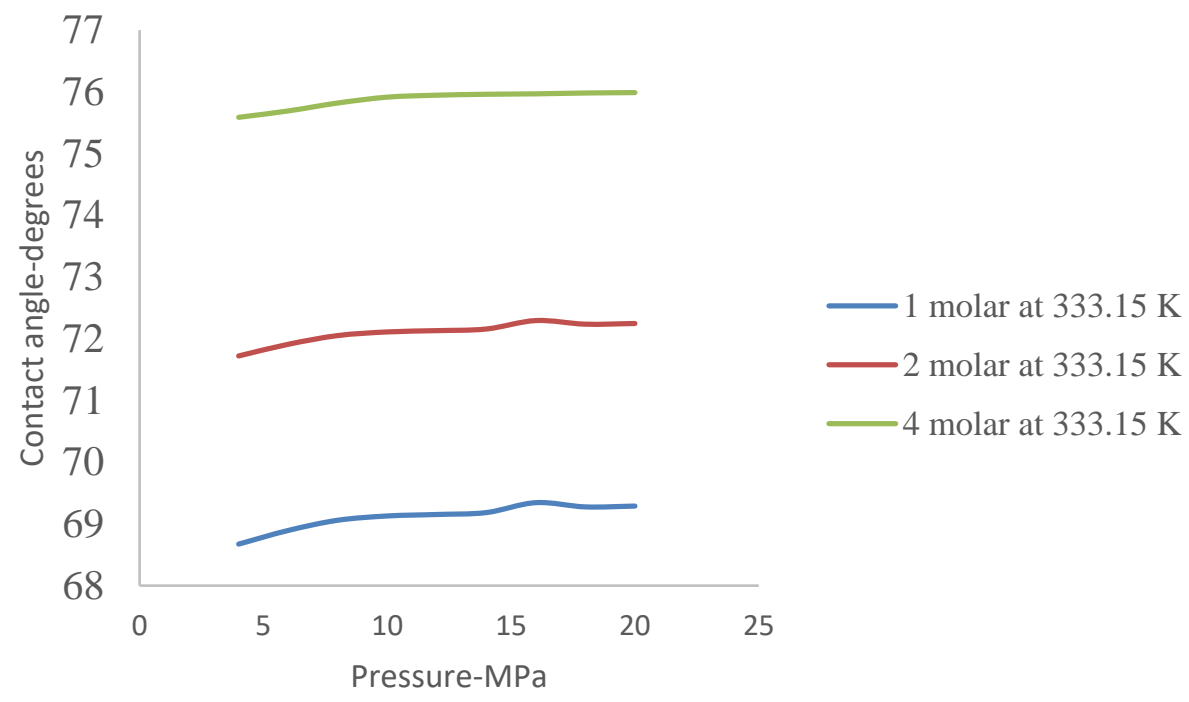

Figure 2. Plot of contact angle versus pressure deduced from Spycher et al 2005), solubility data using our model 


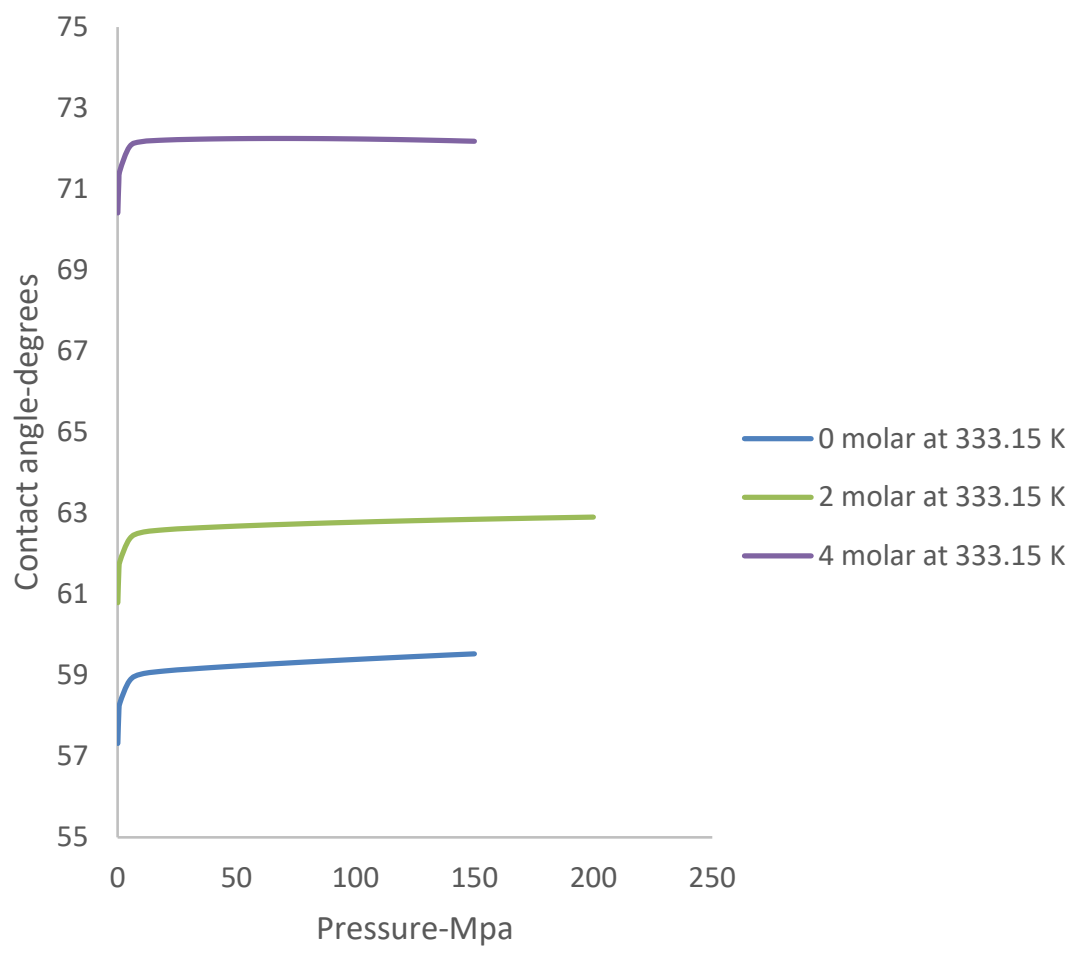

Figure 3. Plot of contact angle versus pressure deduced from Dun and Sun (2003) using solubility data our model

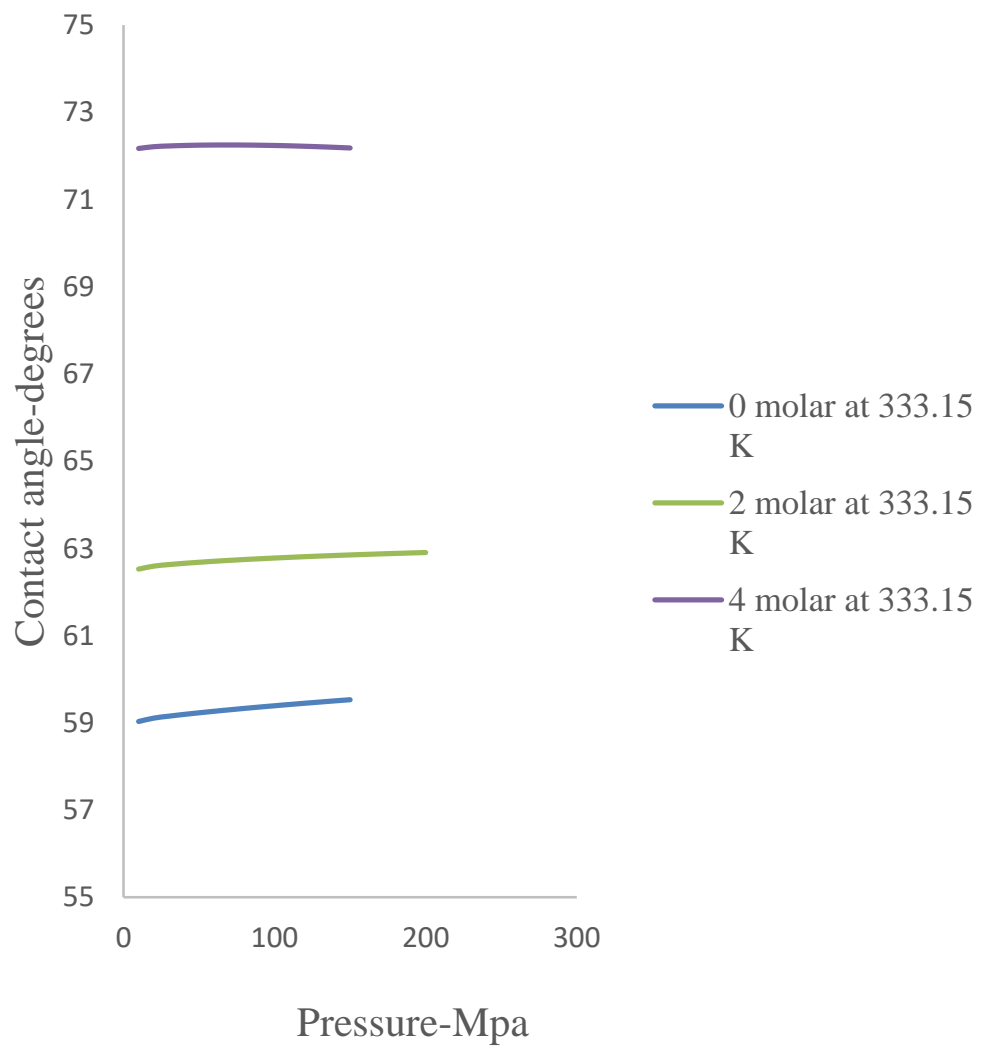

Figure 4. Plot of contact angle versus pressure deduced from Dun and Sun solubility data for pressure starting from 10 $\mathrm{MPa}$, using our model

In all plots above, carbon dioxide dewetting of silica surface at a given temperature is most pronounced where the salinity is higher, also consistent with the plots of (Jung \& Wan, 2012) for a temperature of $318.15 \mathrm{~K}$. 


\subsection{Conclusion}

Solubility of injected carbon dioxide in saline aquifers is the principal cause of $\mathrm{pH}$ evolution from neutral to values below 3 units (Kharaka et al., (2006). Strongly linked to $\mathrm{pH}$ evolution is the phenomenon of $\mathrm{pH}$ induced surface charging of amphoteric surfaces (Kosmulski, 2010), which results in sold-liquid interfacial tension increases for the case of carbon dioxide injection into saline aquifer. In this regard, the Gibb's excess adsorption equation links change in solid-liquid interfacial tension to surface coverage which together with the classical Nernst equation and the phenomenological Young's equation provide the requisite thermodynamic impetus for modeling $\mathrm{pH}$ versus contact angle equation. In this study, we have successfully modelled $\mathrm{pH}$ versus contact angle equation by exploiting a thermodynamic theory relating to surface charge density. Since carbon dioxide solubility under geological conditions of sequestration is given as a function of pressure for a given salinity and temperature, it is possible to link $\mathrm{pH}$ to contact angle and pressure. The following sum up the conclusion of this theoretical study:

1. Contact angle versus $\mathrm{pH}$ for a saline aquifer under geological carbon storage due to $\mathrm{pH}$ evolution in response to dissolved injected carbon dioxide can be described by a logarithmic function,

2. The relationship between $\mathrm{pH}$ and pressure provides the opportunity to plot contact angle versus pressure,

3. Plots of contact angle versus pressure has a step gradient for pressures below the critical pressure of carbon dioxide and a gradient approaching zero for pressures above $10 \mathrm{MPa}$, which agrees with observed experimental trends in the literature (Jung \& Wan, 2012),

4. Based on the model derived in this study, the higher the salinity the bigger is the contact angle at a given pressure for a given temperature, which is also consistent with literature source data (Jung \& Wan, 2012).

Appendix A: Effect of ionic strength on carbon dioxide brine interfacial tension (Saraji, Piri, \& Goual, 2014)

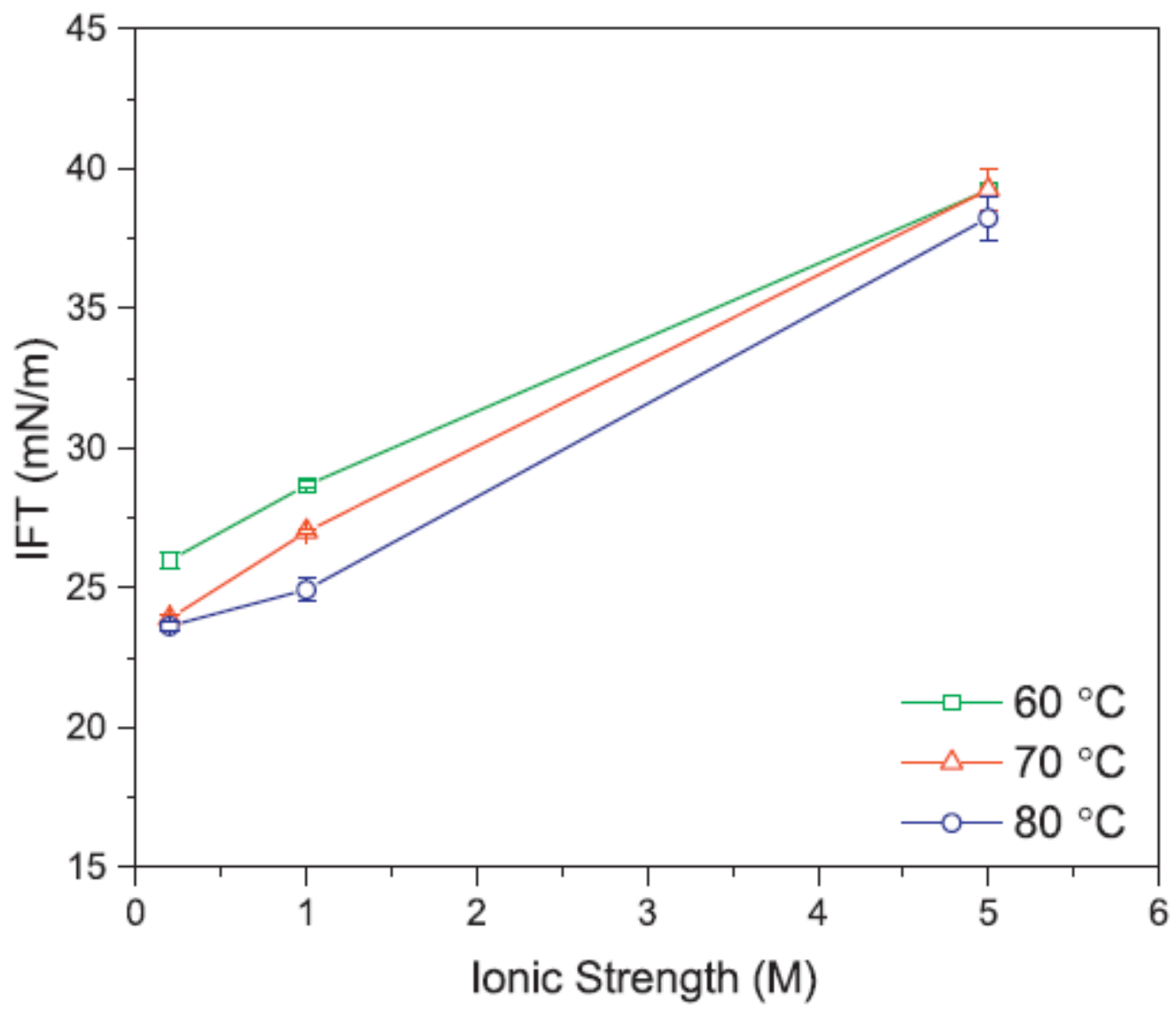


Appendix B: Contact angle versus pressure at 318 K (Jung and Wan, 2012)

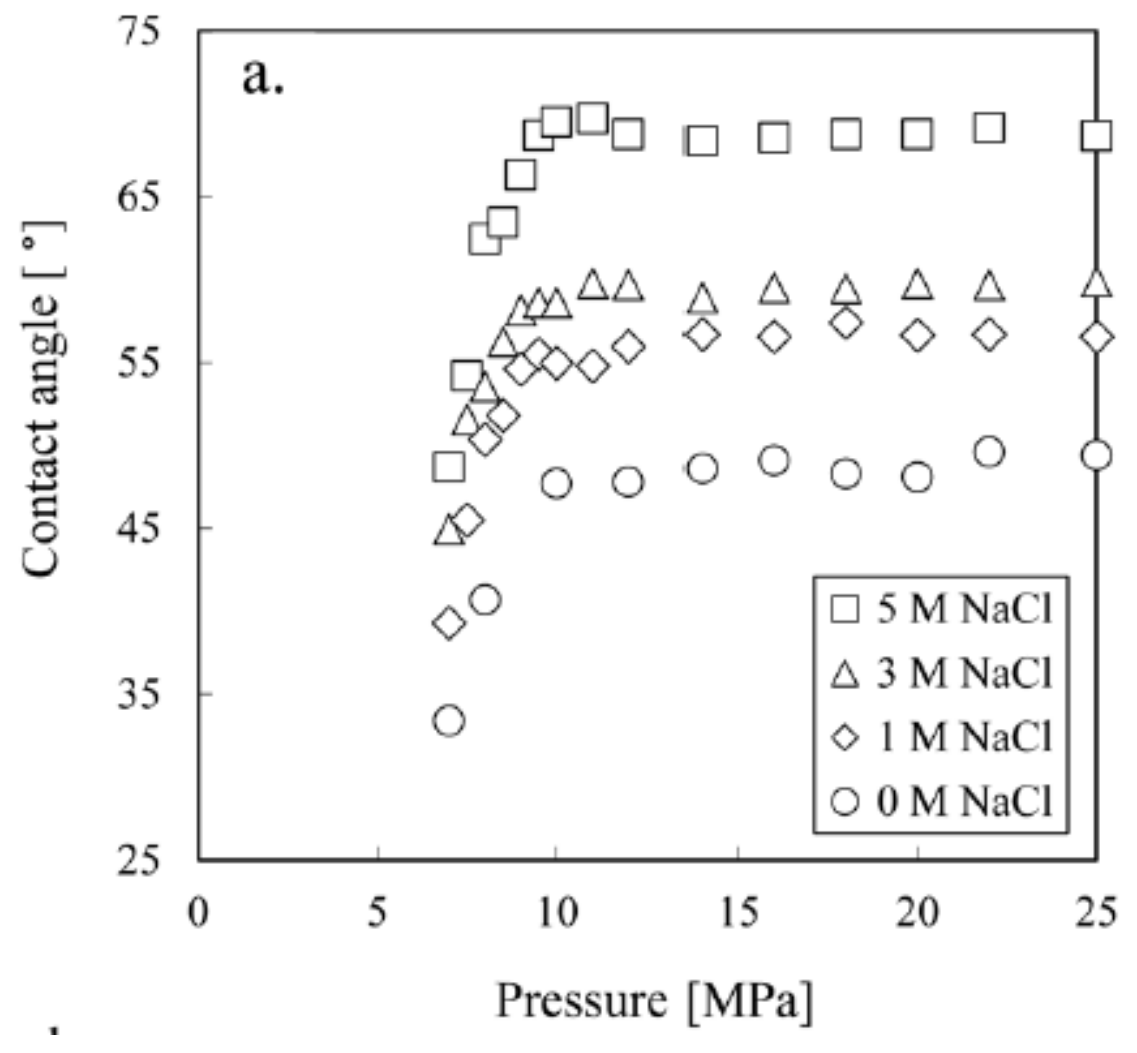

\section{References}

Aissa, M. F., Bahloul, S. M. Y., \& Le-Bail, A. (2015). Effect of Temperature on the Solubility of CO2. International Journal of Food Properties, 18, 1097-1109. https://doi.org/10.1080/10942910903176360

AlQuraishi, A. A., \& AlHussinan, S. N. (2015). Efficiency and Recovery Mechanisms of Low Salinity Water Flooding in Sandstone and Carbonate Reservoirs. Offshore Mediterranean Conference and Exhibition, 25-27 March, Ravenna, Italy. Ravenna, Italy: Offshore Mediterranean Conference.

Amadu, M., \& Miadonye, A. (2017). Determination of the Point of Zero Charge pH of Borosilicate Glass Surface Using Capillary Imbibition Method. International Journal of Chemistry, 9(3), 67-84. https://doi.org/10.5539/ijc.v9n3p67

Amadu, M., \& Miadonye, A. (2019). Derivation of a pH Dependent Solid-Liquid Interfacial Tension and Theoretical Interpretation of the Physicochemistry of Dewetting in the CO2-Brine-Silica System. International Journal of Chemistry, 11(2), 127-155. https://doi.org/10.5539/ijc.v11n2p127

Ashraf, A., Hadia, N., Torsaeter, O., \& Tweheyo, M. T. (2010). Laboratory investigation of low salinity waterflooding as secondary recovery process: effect of wettability. SPE Oil and Gas India Conference and Exhibition. Society of Petroleum Engineers. https://doi.org/10.2118/129012-MS

Azam, M. R., Tan, I. M., Ismail, L., Mushtaq, M., Nadeem, M., \& Sagir, M. (2013). Static adsorption of anionic surfactant onto crushed Berea. J Petrol Explor Prod Technol, 3, J Petrol Explor Prod Technol (2013) 3, 195-201. https://doi.org/10.1007/s13202-013-0057-y

Behrens, S. H., \& Grier, D. G. (2001). The Charge of Glass and Silica Surfaces. J. Chem. Phys., 115, 6716-6721. https://doi.org/10.1063/1.1404988

Chalbaud, C., Robin, M., Lombard, J.-M., Bertin, H., \& Egermann, P. (2010). Brine/CO2 Interfacial Properties and Effects on CO2 Storage in Deep Saline Aquifers. Oil \& Gas Science and Technology, 65(4), 541-555. https://doi.org/10.2516/ogst/2009061

Chattorage, D. (2001). Thermodynamics of Adsorption at Interfaces and the Gibbs Surface Excess. PINAS, 67(6), 663-685.

Ciunel, K., Armélin, M., Findenegg, G. H., \& Klitzing, R. v. (2005). Evidence of Surface Charge at the Air/Water 
Interface from Thin-Film Studies on Polyelectrolyte-Coated Substrates. Langmuir, 21(11), 4790-4793. https://doi.org/10.1021/la050328b

Cooke, D. R., Large, R., Bull, S., \& McGoldrick, P. J. (2000). The Importance of Oxidized Brines for the Formation of Australian ProterozoicStratiform Sediment-Hosted Pb-Zn. Economic Geology, 95(1), 1-18. https://doi.org/10.2113/gsecongeo.95.1.1

Dávila, G., Luquot, L., Soler, J. M., \& Cama, J. (2016). Interaction between a fractured marl caprock and CO2-rich sulfate solution under supercritical CO2 conditions. International Journal of Greenhouse Gas Control, 48, 105-119. https://doi.org/10.1016/j.ijggc.2015.11.005

Ding, H., \& Rahman, S. (2017). Experimental and theoretical study of wettability alteration during low salinity water flooding-an state of the art review. Colloids and Surfaces A: Physicochemical and Engineering Aspects, 520(5), 622-639. https://doi.org/10.1016/j.colsurfa.2017.02.006

Dove, P. M., \& Craven, C. M. (2005). Surface charge density on silica in alkali and alkaline earth chloride electrolyte solutions. Cosmochim. Acta, 69(21), 4963-4970. https://doi.org/10.1016/j.gca.2005.05.006

Duan, Z., \& Sun, R. (2003). An improved model calculating CO2 solubility in pure water and aqueous $\mathrm{NaCl}$ solutions from 273 to $533 \mathrm{~K}$ and from 0 to 2000 bar. Chemical Geology, 193(3-4), 257-271. https://doi.org/10.1016/S0009-2541(02)00263-2

Ehrenberg, S. N., \& Nadeau, P. H. (2005). Sandstone vs. carbonate petroleum reservoirs: A global perspective on porosity-depth and porosity-permeability relationships. AAPG Bulletin, 89(4), 435-445. https://doi.org/10.1306/11230404071

Eliaz, N., Shmueli, S., Shur, I., Benayahu, D., Aronov, D., \& Rosenman, G. (2009). The effect of surface treatment on the surface texture and contact angle of electrochemically deposited hydroxyapatite coating and on its interaction with bone-forming cells. Acta biomaterialia, 5(8), 3178-3191. https://doi.org/10.1016/j.actbio.2009.04.005

Fairbank, M. J., Peter, R. W., \& Fatunmb, H. O. (1997). Mixed Self-Assembled Monolayers in Chemical Separations. Science 03 Jan 1997, 275(5296), 44-47. https://doi.org/10.1126/science.275.5296.44

Farokhpoor, R., Bjørkvik, B. J., Lindeberg, E., \& Torsæter, O. (2013). CO2wettability behavior during CO2sequestration insaline aquifer -An Experimental study on mineralsrepresenting sandstone and carbonate. Energy Procedia, 37, 5339-5351. https://doi.org/10.1016/j.egypro.2013.06.452

Frank, J. M., Pierrot, D., Lee, K., Wanninkhof, R., Richard Feelyc, C. L., Keyd, R. M., \& Takahashi, T. (2002). Dissociation constants for carbonic acid determined from field measurements. Deep-Sea Research, 49, 1705-1723. https://doi.org/10.1016/S0967-0637(02)00093-6

Giovambattista, N., Debenedetti, P. G., \& Rossky, P. J. (2007). Effect of surface polarity on water contact angle and interfacial hydration structure. he Journal of Physical Chemistry B, 111(32), 9581-9587. https://doi.org/10.1021/jp071957s

Godt, R. (1981). A simple electrostatic model can explain the effect of $\mathrm{pH}$ upon the force-pCa relation of skinned frog skeletal muscle Fibres. Biophysics. J., 39, 1981 385-392. https://doi.org/10.1016/S0006-3495(81)84797-2

Hall, A. C., Collins, S. H., \& Melrose, J. C. (1983). Stability of aqueous wetting films in Athabasca tar sands. Society of Petroleum Engineers Journal, 23(02), 249-258. https://doi.org/10.2118/10626-PA

Hanaor, D., Michelazzi, M., Leonelli, C., \& Sorrell, C. (2012). The effects of carboxylic acids on the aqueous dispersion and electrophoretic deposition of $\mathrm{ZrO} 2 . \quad J$. Eur. Ceram. Soc., 32, 235-244. https://doi.org/10.1016/j.jeurceramsoc.2011.08.015

Hanor, J. S. (1994). Origin of saline fluids in sedimentary basins. Geological Society, London, Special Publications, 78 , 151-174. https://doi.org/10.1144/GSL.SP.1994.078.01.13

Illés, E., \& Tombácz, E. (2006). The effect of humic acid adsorption onpH-dependent surface charging and aggregation of magnetite nanoparticles Journal of Colloid and Interface Science. Journal of Colloid and Interface Science, 295(1), 115-123. https://doi.org/10.1016/j.jcis.2005.08.003

Jafari, M., \& Jung, J. (2020). Variation of Contact Angles in Brine/CO2/Mica System considering Short-Term Geological CO2 Sequestration Condition. Geofluid, 1-15. https://doi.org/10.1155/2018/3501459

Jung, J. W., \& Wan, J. (2012). Supercritical CO2 and ionic strength effects on wettability of silica surfaces: Equilibrium contact angle measurements. Energy \& Fuels, 26(9), 6053-6059. https://doi.org/10.1021/ef300913t

Jung, J., \& Wan, J. (2011). Wettability alteration upon reaction with ScCO2: Silica, mica, and calcite. American 
Geophysical Union Fall Meeting. American Geophysical Union.

Katmar-Software. (2020). Values of the Universal Gas Constant " $R$ " in various units. Retrieved from https://www.katmarsoftware.com/gconvals.htm

Kharaka, Y., Cole, D., Hovorka, S., Gunter, W., Knauss, K., \& Freifeld, B. (2006). Gas-water-rock interactions in Frio Formation following $\mathrm{CO} 2$ injection: Implications for the storage of greenhouse gases in sedimentary basins. Geology, 34, 577-580. https://doi.org/10.1130/G22357.1

Kim, Y., Wan, J., Kneafsey, T. J., \& Tokunaga, T. K. (2012). Dewetting of silica surfaces upon reactions with supercritical $\mathrm{CO} 2$ and brine: pore-scale studies in micromodels. Environmental science \& technology, 47(7), 4228-4235. https://doi.org/10.1021/es204096w

Kosmulski, M. (2010). The pH dependent surface charging and points of zero charge. VI. Update. Journal of Colloid and Interface Science, 353. https://doi.org/10.1201/9781420051896

Kosmulski, M. (2016). Isoelectric points and points of zero charge of metal (hydr)oxides: 50years after Parks' review. Adv Colloid Interface Sci, 238, 1-61. https://doi.org/10.1016/j.cis.2016.10.005

Labus, K., Tarkowski, R., \& Wdowin, M. (2015). Modeling gas-rock-water interactions in carbon dioxide storage capacity assessment: a case study of Jurassic sandstones in Poland. Int. J. Environ. Sci. Technol. 12, 2493-2502. https://doi.org/10.1007/s13762-014-0652-6

Lee, J. D. (2020). Why does hydration of ions depend on their charge to area ratio? Retrieved from https://chemistry.stackexchange.com/questions/90571/why-does-hydration-of-ions-depend-on-their-charge-to-arearatio

Li, J., Wei, L., \& Li, X. (2015). An improved cubic model for the mutual solubilities of CO2-CH4-H2S-brine systems to high temperature, pressure and salinity. 54, 1-12. https://doi.org/10.1016/j.apgeochem.2014.12.015

Liu, H. T., Atallah, T., \& Barghouty, M. (2012). The role of CO2 capture and storage in Saudi Arabia's energy future. Int J Greenh, 11, 163-71. https://doi.org/10.1016/j.ijggc.2012.08.008

Mahani, H., Keya, A. L., Berg, S., \& Nasralla, R. (2017). Electrokinetics of carbonate/brine interface in low-salinity waterflooding: Effect of brine salinity, composition, rock type, and $\mathrm{pH}$ on $\zeta$-potential and a surface-complexation model. SPE Journal, 22(1), 53-68. https://doi.org/10.2118/181745-PA

Makkonen, L. (2016). Young's equation revisited. Journal of Physics: Condensed Matter, 28(13), 1-4. https://doi.org/10.1088/0953-8984/28/13/135001

Mehana, M., \& Fahes, M. M. (2018). Investigation of Double Layer Expansion in Low-Salinity Waterflooding: Molecular Simulation Study. SPE Western Regional Meeting, 22-26 April, Garden Grove, California, USA. California, USA: Society of Petroleum Engineers. https://doi.org/10.2118/190106-MS

Moulin, P., \& Roques, H. (2003). Zeta potential measurement of calcium carbonate. J. Colloid Interface Sci., 261, 115-126. https://doi.org/10.1016/S0021-9797(03)00057-2

Nita, S., Do-Quang, M., Wang, J., Chen, Y.-C., Suzuki, Y., Amberg, G., \& Shiomi, J. (2017). Electrostatic cloaking of surface structure for dynamic wetting. Science Advances, 3(2). https://doi.org/10.1126/sciadv.1602202

Parks, G. A. (1984). Surface and interfacial free energies of quartz. Journal of Geophysical Research: Solid Earth, 89(B6), 3997-4008. https://doi.org/10.1029/JB089iB06p03997

Puah, L. S., Sedev, R., Fornasiero, D., Ralston, J., \& Blake, T. (2010). Influence of Surface Charge on Wetting Kinetics. Langmuir , 26(22), 17218-17224. https://doi.org/10.1021/la103351t

Qafoku, N. P., Zheng, L., Bacon, D., \& Lawter, A. (2015). A Critical Review of the Impacts of Leaking CO2 Gas and Brine on Groundwater Quality. Prepared for the U.S. Department of Energy under Contract DE-AC05-76RL01830. https://doi.org/10.2172/1347881

Rathnaweera, T. D., Ranjith, P. G., \& Perera, M. S. (2016). Experimental investigation of geochemical and mineralogical effects of $\mathrm{CO} 2$ sequestration on flow characteristics of reservoir rock in deep saline aquifers. Scientific Reports, 1-12. https://doi.org/10.1038/srep19362

Revil, A. (1998). Nature of surface electrical conductivity. Geophysical Research Letter, 25(5), 691-694. https://doi.org/10.1029/98GL00296

Rusanov, A. I., Shchekin, A. K., \& Tatyanenko, D. V. (2004). The line tension and the generalized Young equation: the choice of dividing surface. Colloids and Surfaces A: Physicochemical and Engineering Aspects, 250(1-3), 263-268. https://doi.org/10.1016/j.colsurfa.2004.04.087 
Saraji, S., Goual, L., Piri, M., \& Plancher, H. (2013). Wettability of supercritical carbon dioxide/water/quartz systems: Simultaneous measurement of contact angle and interfacial tension at reservoir conditions. Langmuir, 29(23), 6856-6866. https://doi.org/10.1021/la3050863

Saraji, S., Piri, M., \& Goual, L. (2014). The effects of SO2contamination, brine salinity, pressure, andtemperature on dynamic contact angles and interfacial tension ofsupercritical $\mathrm{CO} 2 /$ brine/quartz systems. International Journal of Greenhouse Gas Control, 28, 147-155. https://doi.org/10.1016/j.ijggc.2014.06.024

Schneider, A. C., Pasel, C., Luckas, M., Schmidt, K. G., \& Herbell, J. D. (2004). Determination of Hydrogen Single Ion Activity Coefficients in Aqueous $\mathrm{HCl}$ Solutions at 25 ${ }^{\circ}$ C. Journal of Solution Chemistry, 33(3), 257-273. https://doi.org/10.1023/B:JOSL.0000035359.00943.14

Springer, R. D., Wang, Z., Anderko, A., Wang, P., \& Felmy, A. R. (2012). A thermodynamic model for predicting mineral reactivity in supercritical carbon dioxide: I. Phase behavior of carbon dioxide-water-chloride salt systems across the H2O-rich to the CO-rich regions. Chemical Geology, 322, 151-171. https://doi.org/10.1016/j.chemgeo.2012.07.008

Spycher, N., Pruess, K., \& Moridis, G. (2005). A thermodynamic model for mutual solubility of water and CO2 in brines. Proceedings of the 7th International Conference on Greenhouse Gas Control Technologies 5- September 2004, Vancouver, Canada. 7, 2055-2058. Greenhouse Gas Control Technologies. https://doi.org/10.1016/B978-008044704-9/50271-8

Tokunaga, T. K. (2012). DLVO-based estimates of adsorbed water film thicknesses in geologic CO2 reservoirs. Langmuir, 28(21), Langmuir, 28(21), 8001-8009. https://doi.org/10.1021/la2044587

Yang, J., Dong, Z., Dong, M., Yang, Z., Lin, M., Zhang, J., \& Chen, C. (2016). Wettability alteration during low-salinity waterflooding and the relevance of divalent ions in this process. Energy \& Fuels, 30(1), 72-79. https://doi.org/10.1021/acs.energyfuels.5b01847

Yoo, D., Shiratori, S., \& Rubner, M. (1998). Macromolecules, 31(4309). https://doi.org/10.1021/ma9800360

Zhou, Q., Birkholzer, J., Mehnert, E., \& Lin, Y. Z. (2010). basin-and plume-scale processes of CO2 deployment. Groundwater, 48(4), 494-514. https://doi.org/10.1111/j.1745-6584.2009.00657.x

Zhuravlev, L. T., \& Potapov, V. V. (2006 ). Density of silanol groups on the surface of silica precipitated from a hydrothermal solution. Russian Journal of Physical Chemistry, 80(7), 1119-1128. https://doi.org/10.1134/S0036024406070211

\section{Copyrights}

Copyright for this article is retained by the author(s), with first publication rights granted to the journal.

This is an open-access article distributed under the terms and conditions of the Creative Commons Attribution license (http://creativecommons.org/licenses/by/4.0/). 